\title{
Estimation of the return period of rockfall blocks according to their size
}

\author{
Valerio De Biagi ${ }^{1}$, Maria Lia Napoli ${ }^{1}$, Monica Barbero ${ }^{1}$, and Daniele Peila ${ }^{2}$ \\ ${ }^{1}$ Department of Structural, Geotechnical and Building Engineering, Politecnico di Torino, Corso Duca degli Abruzzi 24, \\ 10129 Turin, Italy \\ ${ }^{2}$ Department of Environmental and Infrastructural Engineering, Politecnico di Torino, Corso Duca degli Abruzzi 24, \\ 10129 Turin, Italy
}

Correspondence to: Valerio De Biagi (valerio.debiagi@polito.it)

Received: 1 July 2016 - Published in Nat. Hazards Earth Syst. Sci. Discuss.: 5 July 2016

Revised: 12 December 2016 - Accepted: 27 December 2016 - Published: 30 January 2017

\begin{abstract}
With reference to the rockfall risk estimation and the planning of rockfall protection devices, one of the most critical and most discussed problems is the correct definition of the design block by taking into account its return period. In this paper, a methodology for the assessment of the design block linked with its return time is proposed and discussed, following a statistical approach. The procedure is based on the survey of the blocks that were already detached from the slope and had accumulated at the foot of the slope in addition to the available historical data.
\end{abstract}

\section{Introduction}

Rockfall is one of the most critical slope instabilities because it can be highly destructive and unpredictable. The analysis of this phenomenon is very difficult because it is affected by aleatory variability (irreducible natural variability) and epistemic uncertainty (lack of knowledge). For these reasons, probabilistic methods are a suitable approach for modelling rockfall. When risk analysis has to be performed for forecasting and protection purposes, the size of the involved blocks and the corresponding return period are the most important variables among the ones that characterize the phenomenon (Peila et al., 1998, 2006; Peila and Ronco, 2009).

Modern design approaches for buildings, for example, aim to guarantee the structural safety of the building throughout its expected lifetime. In such reliability-based framework, the buildings have to be robust, i.e. to support forces due to anthropic and natural hazards without being significantly dam- aged. Proper design processes for common natural hazards, such as extreme winds or seisms, are already present in the building codes (Elishakoff, 1999; ISO, 1998; Leporati, 1979; Madsen et al., 2006; Melchers, 1999); these define the magnitude of the external force on the base of the probability of exceeding such intensity during the design life of the structure. In addition, the structural safety must be guaranteed on the base of the consequences caused by natural hazards on the structure (vulnerability).

Dealing with natural hazards, one of the common ways to input the external forces applied to the structures is to establish a link between the magnitude of the forces and the corresponding return period. A larger return period implies higher intensity in the force. In a recent work, De Biagi et al. (2016a) proposed a reliability-based design procedure for structures subjected to snow-avalanche hazards.

The magnitude-frequency relationship is at the basis of the probabilistic hazard analysis. In seismic analysis, the Gutenberg-Richter law expresses such relationship. Straub and Schubert (2008) proposed a probabilistic approach for rockfall risk assessment based on a frequency law, but did not investigate its nature. Lari et al. (2014) considered the annual frequency of occurrence of a rockfall volume as "given" data. The proposed approach intends to be the base for more complex and complete probabilistic hazard assessments.

In designs of engineering works that protect a village or a road from falling rocks (e.g. net fences or embankments), the size of the falling block used in the modelling is currently not linked to its probability of occurrence, i.e. the return period of a block with such volume. The most frequently ap- 
plied approaches refer to an analysis of the blocks that had already collapsed, integrated with a survey of the slope. The size of the falling design block is chosen from among the already collapsed blocks and the surveyed blocks of the slope.. Adapting the well-known procedures of modern design practice requires that the sizes of the falling blocks have to be related to their probability of occurrence and vice versa.

Examples of volume-frequency laws are proposed in the literature. They are obtained from the analysis of a large number of rockfall events for which each observed event is dated and the volume is estimated. This allows a volumefrequency curve to be drawn, in which each point corresponds to an observation. In general, precise catalogues with a large number of events are rare because the road owners or the territorial administrations started the records of events, which have large return periods, only some tens of years ago. For common uses, e.g. design of protective devices or risk estimation, for which there are no long records of events nor detailed surveys on site, no operative procedures are consolidated and the designer develops the project following his personal experience. In any case, the choice of the "characteristic block volume" (design volume) has to be done by the designer's own engineering judgement. For this reason, it is affected by subjectivity.

With the aim of contributing to overcoming this design problem, this paper proposes a methodology for estimating the block volume-frequency relationship that can be used for deriving the size of the falling design block having a prescribed return period. The procedure, which is described in detail in Sect. 3, is based on the data reported in rockfall inventories and on surveys at the foot of the slope, managed following a statistical procedure.

\section{Power laws in rockfall analysis}

Statistical analyses of historical data or experimental tests related to a certain natural phenomenon give evidence that it is possible to deduce power laws that link the magnitude of the event to its frequency. These mathematical relationships can be used for predicting type, extent, return time and magnitude of future events.

In the fifties, Gutenberg and Richter (1956) observed that there was a relationship between the cumulative number of earthquake events exceeding a given value of magnitude $N(m \geq M)$ and the magnitude itself. They formulated the following law:

$\log N(m \geq M)=\alpha-\beta M$,

where $\alpha$ and $\beta$ are site-dependent constants. More recently, as for earthquakes, statistical analyses of historical data sets have been widely applied to derive the recurrence rate of events of a given magnitude for other natural phenomena such landslides, rockfalls, snow avalanches, etc. (Dussauge-
Peisser et al., 2002; De Biagi et al., 2012; Corominas et al., 2014).

The analysis of historical data, which are available in public archives or catalogues, is therefore extremely important for the study of natural phenomena. With particular reference to landslides and rockfalls, this statistical approach has been recently studied and applied by several authors in many mountain sites. Research has mainly focused on the analysis of the volume distribution of rockfall events for the sites of Grenoble, Yosemite Valley, Arly gorges, British Columbia, Hong Kong, Italian Apennines, Aosta Valley, ChristchurchCanterbury and La Réunion Island (Dussauge-Peisser et al., 2002; Dussauge et al., 2003; Keith Turner and Schuster, 2012; Abbruzzese et al., 2009; Brunetti et al., 2009; De Biagi et al., 2016b; Guzzetti et al., 1994; Lari et al., 2014).

The comparison of the previous studies showed that negative power laws fit all rockfall recurrence volume distributions well. However, some variability in the values assigned to the power law coefficients does appear. This has been mainly attributed to the variability in the sampling procedures of the landslide volumes. At present, no proper test equipment (which provide, as for earthquakes, objective and reliable values that are comparable from one site to another) and standard procedures have been defined for the different geological and structural settings where rockfalls may occur (Brunetti et al., 2009).

Rockfall inventories do not always contain quantitative and detailed information, and the description of historical events is often characterized by a low degree of accuracy. For example, in the Yosemite rockfall inventory (Wieczorek and Snyder, 2004; Guzzetti et al., 2003), which can be considered one of the largest detailed rockfall inventories, the exact locations of rockfalls, the detachment areas and the block volumes (or weights) are not always given. More often, size and triggering information of the events is given in a qualitative and incomplete way; temporal information is not precise. Rockfalls that occurred within a few hours from the same source area are sometimes listed as the same event, overestimating their magnitude. In general, a lack of data on smaller rock blocks subsists while large and more damaging rockfalls were recorded regularly. Thus, it is clear that a certain degree of uncertainty and lack of homogeneity in the collected data exist.

Previous considerations, which have to be taken into account in treating historical data, are related to Yosemite Valley but can be easily referred to almost all of the historical archives (Corominas et al., 2014; Brunetti et al., 2009; Corominas et al., 2005).

In addition, the temporal length of the observations can affect the recurrence volumetric distribution. In particular, a few years time window underestimates larger collapses. Many authors examined the frequency-size distributions of both rockfalls and fallen blocks and noted that the cumulative frequency is linearly related to the magnitude (block volume or rockfall volume) on a log-log plot. In mathematical terms, 


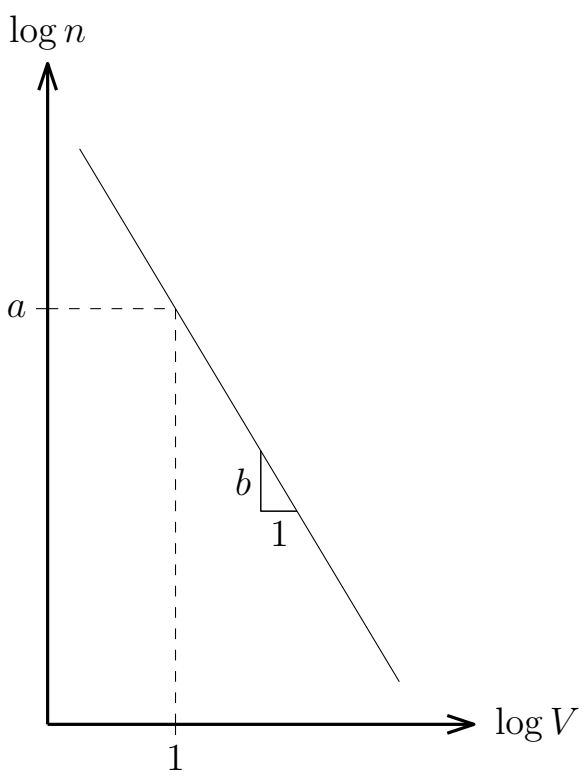

Figure 1. Sketch of a $n=a V^{-b}$ power law relationship.

the following power law relationship subsists:

$n(v \geq V)=a V^{-b}$,

where $n(v \geq V)$ is the frequency of blocks volume (or rockfalls volume) with size larger than $V$ (generally, the size is expressed in $\mathrm{m}^{3}$ ), while $a$ and $b$ are constants: $a$ relates to the frequency of blocks volume (or rockfalls volume) larger than a unit volume (i.e. $1 \mathrm{~m}^{3}$ ) and $b$ represents the slope of the regression line or the fractal dimension (Turcotte, 1997), as sketched in Fig. 1. With reference to the example of Fig. 1, if the volumes are expressed in cubic metres, $a$ is the annual frequency of occurrence of a rockfall larger than $1 \mathrm{~m}^{3}$. In this case, supposing $V=2.5 \mathrm{~m}^{3}, n(v \geq V)$ is the annual frequency of volumes larger than $2.5 \mathrm{~m}^{3}$.

This formulation implies that (i) larger rockfall events are less frequent than those characterized by smaller size and (ii) frequency-size distributions are well fitted by a power law only over a given range of volumes. The power law exhibits a deviation from the observed distribution for volumes smaller than a certain value. This discrepancy has been discussed in the literature. It can be the result of undersampling of the smallest rockfall events (Brunetti et al., 2009; Stark and Hovius, 2001). While collapses of considerable sizes are easily identifiable and are almost always recorded, collapses of very small sizes, mainly causing no damage, are unnoticed and, especially in the past, they have been rarely reported in the archives. In addition, the formulation implies that rockfalls on huge scales can be considered more reliable as the recording time increases.

Regarding power laws that are applied to rockfall volumes, the values of the parameters of Eq. (2) are variable. Dussauge-Peisser et al. (2002) analysed a range of volumes spanning from $10^{1}$ to $10^{6} \mathrm{~m}^{3}$ and suggested that $b$ is not dependent on the scale of study, slope lithology and fracture systems. Other authors propose different values of $b$, depending on the degree of fracturing: the less the rockmass fracturing, the smaller the $b$ value. Various studies have been performed for rockfalls less than $10 \mathrm{~m}^{3}$ (Gardner, 1970; Hungr et al., 1999), also by means of topographical techniques down to $10^{-3} \mathrm{~m}^{3}$ (Rosser et al., 2005; Abellán et al., 2010; Dewez et al., 2013). Dai and Lee (2001) studied 2811 landslides and rockfalls and Rousseau (1999) used seismic monitoring technique. On the contrary, coefficient $a$ exhibits relevant fluctuation from one site to another.

As mentioned, Eq. (2) can be related to the distribution of the volumes of the fallen blocks. The values of the parameters $a$ and $b$ are variable. Parameter $b$ could assume different values in the range 0.5 to 1.3 . Various examples can be found in the literature. Crosta et al. (2007) determined different fractal dimensions in analysing grain size curves obtained from different spots of the deposits of a large rock avalanche that occurred in 1987 in the central Italian Alps. Ruiz-Carulla et al. (2015) carried out a detailed survey in order to highlight the differences in block distribution in various portions of the deposit of a rockfall and found a $b$ value ranging from 0.89 to 1.28 . The same authors analysed the dependency between the free-fall height and the value of $b$ for various well-documented rockfall events in Spain. They found that $b$ increases as the falling height of the block increases (Ruiz-Carulla et al., 2016). Observing the data reported in the previously mentioned paper, it emerges that the lithology of the rock mass affects the value of parameter $b$. For similar free-fall heights, $b=0.72$ was computed for rockfall in limestones and $b=0.92$ for rockfall in schists. The larger the $b$ value, the more comminuted the deposit. Hantz et al. (2016) surveyed four limestone deposits in the area of Grenoble, France, and found $b$ values ranging from 0.63 to 1.12 . Parameter $a$ exhibits relevant variability from one site to another and it is essentially linked to the number of blocks counted on the deposit of the rockfall.

\section{Proposed method}

A three-step procedure for deriving a volume-frequency relationship for blocks with a reduced amount of available data is built up and discussed in the following. Some aspects of the proposed methodology result from hydrological approaches in flood-frequency analyses (see Claps and Laio, 2003). The main hypothesis of the procedure is that the temporal occurrences (i.e. the events) are considered separately from the deposit volumes distribution in a representative area where the rockfall occurs. A representative area is defined as the portion of deposit beyond a defined line, in which the hazard is computed. We consider the foot of the slope as a representative area. 
As described in detail in this section, the required data for deriving a volume-frequency relationship are as follows.

i. A catalogue of events, i.e. events with quantitative rockfall volume estimates observed in the representative area, is denoted as $\mathcal{C}$. Referring to such input, at present, no real-time automatic systems able to detect the occurrence of a rockfall event are diffused. A few examples of monitoring through sensors able to detect microseismic activity are present in the literature. Unfortunately, the calibration of such systems is difficult and the results largely depends on the environmental noises. Other nonreal-time methodologies exist. For example, if the phenomena occur in a forested area, the continuous growing of plants can give information about potential impacts (and tree damages) that occurred in the past (Dorren et al., 2007). Anyway, this method suffers many epistemic uncertainties: the same rockfall event can damage more than one tree, or it is not possible to distinguish between one or more events that occurred during the same plant-growing season (Moya et al., 2010). Alternatively, topographical approaches, e.g. laser scanning, are largely used to monitor rock faces (Abellán et al., 2010, 2011), but a lasting survey campaign is required to get a robust catalogue of events. The direct observation is still the most common, being a simple and cheap solution for drawing up a catalogue of rockfall events. Usually, the local government, road supervisors or forestry service agents are involved in the collection of data related to rockfall events, as reported by Dussauge-Peisser et al. (2002). Since direct observation is affected by errors, in the proposed procedure a threshold volume is considered, as described in the following.

ii. A list of measured volumes that may have fallen down at any time is denoted as $\mathcal{F}$. Referring to such input, different counting procedures have been developed. The simplest method consists of counting the fallen blocks and classifying them into volume classes. Different approaches have been proposed, depending on the size of the rockfall. For example, Corominas et al. (2012) directly counted (and classified) all the fallen blocks in small-scale rockfall events in Andorra. For larger phenomena, Ruiz-Carulla et al. (2015) proposed a methodology for obtaining a rockfall block size distribution (RBSD) essentially based on block counting in small sampling plots and homogenization to the whole debris cover. More complex methods make use of topographic techniques (digital elevation models, orthophotos) to identify the existing discontinuity sets and to compute the volume of the unstable rock blocks on the slope face (Jaboyedoff et al., 2009; Mavrouli et al., 2015). In such cases, the time-magnitude relationship would refer to the release of blocks and fragmentation and comminution should be considered in the propagation analysis. In order to avoid these problems, the authors suggest considering a distribution of volumes obtained from surveys in the representative area.

Obviously, both the catalogue and the list must be related to the same area of the slope, i.e. its foot. All the blocks in catalogue $\mathcal{C}$ are elements of list $\mathcal{F}$. In addition, list $\mathcal{F}$ also contains fallen blocks that have not been observed or recorded. Because of that, its cardinality, i.e. the number of elements, is larger than the one of $\mathcal{C}$.

The first step of the analysis consists of choosing "relevant" events within catalogue $\mathcal{C}$. To this aim, a threshold volume $V_{\mathrm{t}}$ is identified (details on the choice of $V_{\mathrm{t}}$ are provided in Sect. 3.1) and the elements of catalogue $\mathcal{C}$ are split into two sets. The events corresponding to a volume equal to or larger than the threshold volume $V_{\mathrm{t}}$ are included in a reduced catalogue $\mathcal{C}^{*}$ mathematically described as

$\mathcal{C}^{*}=\left\{e: e \in \mathcal{C} \wedge V(e) \geq V_{\mathrm{t}}\right\}$,

where $V(e)$ is the volume associated to falling event $e$. The events not satisfying this condition were discarded, thus not considered in the analysis. List $\mathcal{F}$ is treated in the same way: a list $\mathcal{F}^{*}$ including all the volumes equal or larger than the threshold volume $V_{\mathrm{t}}$ is set up:

$\mathcal{F}^{*}=\left\{s: s \in \mathcal{F} \wedge V(s) \geq V_{\mathrm{t}}\right\}$,

where $V(s)$ is the volume associated to the $s$ th record of the survey at the foot of the slope (in the representative area). As before, the surveyed volumes smaller than $V_{\mathrm{t}}$ are not further considered in the analysis.

The second step of the analysis consists of the choice of two probabilistic models. One should be able to describe the temporal occurrences of the events of catalogue $\mathcal{C}^{*}$, the other should describe the distribution of the surveyed volumes in list $\mathcal{F}^{*}$. It is assumed that the observed events are independent if the threshold value, $V_{\mathrm{t}}$, is sufficiently high. Thus, the temporal occurrences can be described with a rare-event probabilistic law, i.e. a Poisson distribution. The block sizes at the foot of the slope follow a power law, as previously detailed. A generalized Pareto distribution (GPD) is adopted to describe the sizes of the surveyed blocks in list $\mathcal{F}^{*}$. The GPD has two degrees of freedom and represents a good compromise between the quality of the fitting (which, in general, increases as much as the number of degrees of freedom increases) and the robustness of the model (which depends on the number of observations). GPD is chosen since it well fits the records of list $\mathcal{F}^{*}$, being a power-like distribution, but other probabilistic distributions can be adopted and the proposed procedure easily adapted (Burnham and Anderson, 2003).

Knowing the annual mean number of blocks bigger than $V_{\mathrm{t}}$ (i.e. $\lambda$ ) and the cumulative distribution function of the block volume $F_{V}(v)$, the temporal frequency (the inverse of the return period $T$ ) of blocks bigger than $v$ is

$$
\lambda\left[1-F_{V}(v)\right]=\frac{1}{T} .
$$


Inversely, the volume with return period $T, v_{T}$ is

$v_{T}=F_{V}^{-1}\left(1-\frac{1}{\lambda T}\right)$,

where $F_{V}^{-1}(\cdot)$ is the inverse of the cumulative density function of the probabilistic distribution describing the size of the surveyed blocks, i.e. GPD, $\lambda$ is the annual mean number of events.

The third step of the analysis consists of the estimation of the parameters of the statistical laws by means of the measured rockfall data contained in $\mathcal{C}^{*}$ and $\mathcal{F}$. The former gives the parameter temporal frequency, and the latter the parameters of the GPD.

\subsection{Definition of the threshold volume}

The catalogue of the event $\mathcal{C}$ contains all the recorded events gathered in a time window, i.e. from the beginning to the end of the observation period. For sake of simplicity we consider that the end of catalogue $\mathcal{C}$ coincides with the present time. The catalogue has a temporal length $\tau(\mathcal{C})=t$ and is composed by events related to both small and large rockfall phenomena.

Since the recording of the events is related to in situ observations after the occurrence, events involving small rock blocks are not always recorded. Therefore, there is the possibility that catalogue $\mathcal{C}$ contains only a part of these small events. This fact was considered in the proposed analysis with the introduction of a threshold volume, $V_{t}$, defined as the minimum size of a fallen block that has always been observed and recorded (after its occurrence). This means that the threshold volume is not necessarily the smallest volume in the catalogue of the events $\mathcal{C}$. This concept is similar to the so-called perception threshold in flood-frequency analysis (Claps and Laio, 2003).

A reduced catalogue, which is mathematically described by Eq. (3), is created. The cardinality of $\mathcal{C}^{*}$, i.e. $\left|\mathcal{C}^{*}\right|$, is equal to $n^{*}$ and, as already specified, the events are considered independent. The value of the threshold volume influences the temporal length of $\mathcal{C}^{*}$. Since the decision to monitor a rockfall-prone slope usually begins after the occurrence of an event larger than the threshold volume, it is possible to consider that, in a previous time interval of about half the return period of the events of the reduced catalogue, i.e $t / n^{*}$, no events were recorded. This means that the temporal length of the reduced catalogue is

$t^{*}=\tau\left(\mathcal{C}^{*}\right)=t+\frac{t}{2 n^{*}}$

If $n^{*}$ is large enough, the term $t / n^{*}$ is a good estimate of the return period of the events of the reduced catalogue. In the case $n^{*}=1$, the return period may be strongly underestimated if the observation period is short.

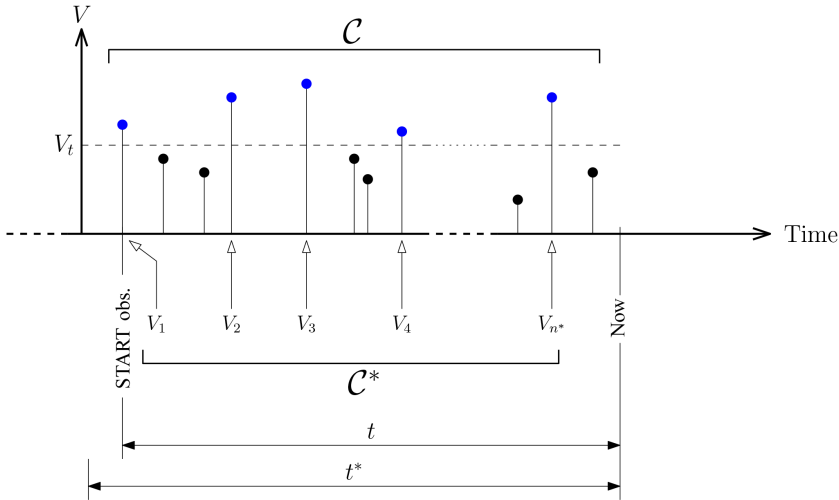

Figure 2. Sketch of the catalogues of events $\mathcal{C}$ and $\mathcal{C}^{*}$. The events with volume $V(e)$ larger than the threshold volume $V_{\mathrm{t}}$ are indicated with blue bullets, those smaller than the threshold volume $V_{\mathrm{t}}$ are indicated with black bullets.

\subsection{Probabilistic model describing the temporal occurrence of the events in $\mathcal{C}^{*}$}

Under the hypothesis of independence between the observations, the rockfall phenomenon is considered to be a completely random process for which any realization consists of a set of isolated stochastically independent points in time (McClung, 1999). In statistics, such a process is known as a Poisson point process. Therefore the events of the reduced catalogue $\mathcal{C}^{*}$ within the temporal range $t^{*}$ are considered to be a realization of a Poisson point process. The mathematical relationship between the probability of occurrence of $n$ events during the observation period $t^{*}$, i.e. the probability mass function, is

$p(n)=\frac{e^{-\lambda t^{*}}\left(\lambda t^{*}\right)^{n}}{n !}$,

where $\lambda>0$ is the so-called parameter of the Poisson distribution. The hypothesis of independent and Poisson distributed rockfall events is essential to relate the cumulative density function of the sizes of the surveyed blocks, $F_{V}(v)$, to that of the annual maxima, $G_{V}(v)$, by means of

$G_{V}(v)=e^{-\lambda\left[1-F_{V}(v)\right]}$.

$G_{V}(v)$ represented the annual probability of occurrence of a block of volume smaller than $v$.

\subsection{Probabilistic model describing the record distribution in $\mathcal{F}^{*}$}

The probabilistic model of the volume distribution at the foot of the slope is determined using the records contained in list $\mathcal{F}^{*}$. As discussed, only blocks larger than the threshold volume, $V_{\mathrm{t}}$, are considered. The generalized Pareto distribution (GPD) is used and it has cumulative distribution function 
equal to

$F_{V}(v)=1-\left(1+\xi \frac{v-\mu}{\sigma}\right)^{-1 / \xi}$

where $\sigma, \xi$ and $\mu$ are scale, shape and location parameters, respectively. The scale parameter is always positive and the distribution has support $v \geq \mu$ for $\xi \geq 0$ or $\mu \leq v \leq \mu-\sigma / \xi$ for $\xi<0$. The location parameter bounds the distribution. Since the volumes smaller than $V_{\mathrm{t}}$ are not considered, the location parameter is equal to threshold volume, i.e. $\mu=V_{\mathrm{t}}$. The inverse of Eq. (10), to be used in Eq. (6), is equal to

$v\left(F_{V}\right)=F_{V}^{-1}\left(F_{V}\right)=\mu+\left[\left(1-F_{V}\right)^{-\xi}-1\right] \frac{\sigma}{\xi}$.

In the present framework, substituting $F_{V}=1-\frac{1}{\lambda T}$, the volume, $v(T)$, corresponding to a return period $T$ years is

$v(T)=\mu+\left[(\lambda T)^{\xi}-1\right] \frac{\sigma}{\xi}$,

and the return period, $T(v)$, corresponding to a volume $v$ is

$T(v)=\frac{1}{\lambda}\left(1+\xi \frac{v-\mu}{\sigma}\right)^{1 / \xi}$

As a consequence, the annual frequency of occurrence, which is the reciprocal of the return period, is

$$
\frac{1}{T}=\lambda\left(1+\xi \frac{v-\mu}{\sigma}\right)^{-1 / \xi}
$$

\subsection{Evaluation of the parameters of the distributions}

An estimate of the parameter $\lambda$ of the Poisson distribution was obtained through the maximum likelihood method. The maximum likelihood estimate is an unbiased estimator of $\lambda$ and was determined as

$\lambda=\frac{n^{*}}{t^{*}}$,

i.e. as the ratio between the cardinality and the length of the time window of catalogue $\mathcal{C}^{*}$.

The estimates of the scale and shape parameters, $\xi$ and $\sigma$, are determined through a maximum likelihood scheme after imposing that the location parameter, $\mu$, is equal to the threshold volume.

\section{Examples}

With the aim of better explaining the proposed methodology, it was applied to two areas affected by rockfalls. Both Buisson and Becco dell'Aquila are located in Aosta Valley, north-western Italian Alps, as shown in Fig. 3.

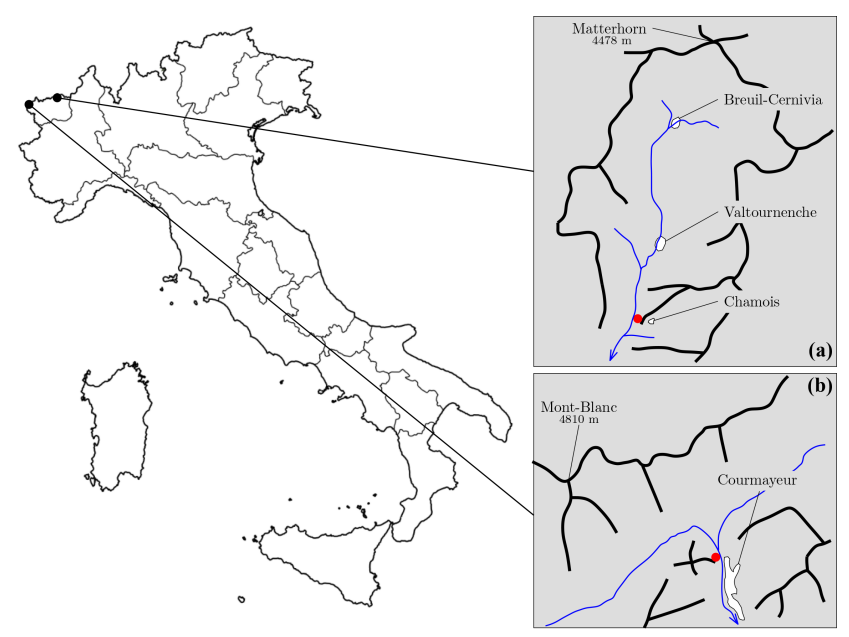

Figure 3. Map of the two test site locations in the north-western Italian Alps. The Buisson site is shown with a red bullet in (a), the Becco dell' Aquila site is shown with a red bullet in (b).

\subsection{Buisson site}

The Buisson site (UTM: 392267, 5077165, 32, T) is located on the left bank of the Marmore torrent in the municipality of Antey-Saint-André in Valtournenche at an altitude ranging from $1130 \mathrm{~m}$ to $1612 \mathrm{~m}$ a.s.l. The source area is composed of gneiss, which are fine- to medium-grained rocks with the dominant foliation plane orientation at 195/35. Discontinuity sets are observed along $270 / 85$ and $320 / 80$ planes, the latter being the orientation of the slope face. The study slope is mainly composed of debris which extend down the slope to the alluvial plain and are covered by irregular (from scanty to very dense) vegetation. The site is close to a camping area, for which protection measures and thus records of rockfall events have been taken since 1994 , when a large block $\left(3 \mathrm{~m}^{3}\right)$ hit a part of the area.

A detailed survey in the deposition area was performed: 60 blocks with volume ranging from 0.02 to $308 \mathrm{~m}^{3}$ were observed and their position recorded through GPS. These data constitute list $\mathcal{F}$ (Table 1). The analysis of the occurrences was done after the historical catalogue of the Regional Geological Service of Aosta Valley that reports five events at the site from 1994 (September 1994, March 1995, September 1996, April 1998, October 2002). Because of the continuous monitoring after the construction of the camping site, all the events after 1994 were recorded and thus considered in catalogue $\mathcal{C}$ and the reduced catalogue $\mathcal{C}^{*}$, which are coincident. The threshold volume $V_{\mathrm{t}}$ was set equal to $0.5 \mathrm{~m}^{3}$, i.e. the minimum size of the observed events in $\mathcal{C}$. The number of events considered in the analysis is equal to $n^{*}=n=5$. The corrected time $t^{*}$ is computed through Eq. (7) and is equal to 25.3 years. Eq. (15) gives $\lambda=0.1976$.

The reduced list, $\mathcal{F}^{*}$, was determined after the definition of the threshold volume; see the right-hand column of Table 1. 
Table 1. Volumes of the surveyed blocks in the deposition area of the Buisson site. The blocks are divided into two classes, depending on their size (smaller or larger than $V_{\mathrm{t}}$ ). All the blocks belong to list $\mathcal{F}$; blocks larger than $V_{\mathrm{t}}$ belong to the reduced list $\mathcal{F}^{*}$.

\begin{tabular}{lcc|cccc}
\hline \multicolumn{3}{c|}{ smaller than $0.5 \mathrm{~m}^{3}$} & \multicolumn{5}{|c}{ larger than $0.5 \mathrm{~m}^{3}$} \\
\hline 0.02 & 0.08 & 0.32 & 0.58 & 1.9 & 8.0 & 58.8 \\
0.03 & 0.10 & 0.39 & 0.59 & 4.1 & 8.0 & 132.2 \\
0.03 & 0.11 & 0.40 & 0.66 & 4.1 & 10.0 & 308.6 \\
0.03 & 0.11 & 0.40 & 1.1 & 4.2 & 11.8 & \\
0.04 & 0.12 & 0.40 & 1.1 & 4.5 & 18.0 & \\
0.04 & 0.14 & 0.42 & 1.3 & 4.8 & 18.2 & \\
0.05 & 0.19 & 0.48 & 1.4 & 5.0 & 18.6 & \\
0.05 & 0.20 & & 1.6 & 5.1 & 19.2 & \\
0.07 & 0.21 & & 1.8 & 6.9 & 21.6 & \\
0.07 & 0.24 & & 1.8 & 7.5 & 24.0 & \\
\hline
\end{tabular}

Table 2. Input and results of the analyses performed at the Buisson site. The estimates of the parameters of the distribution are reported in the bottom rows.

\begin{tabular}{ll}
\hline Obs. & $1994-2016$ \\
\hline$t$ & $23 \mathrm{yr}$ \\
$V_{\mathrm{t}}$ & $0.5 \mathrm{~m}^{3}$ \\
$n$ & 5 \\
$n^{*}$ & 5 \\
$t^{*}$ & $25.30 \mathrm{yr}$ \\
\hline$\lambda$ & 0.1976 \\
$\xi$ & 0.994 \\
$\sigma$ & 4.418 \\
$\mu$ & 0.5 \\
\hline
\end{tabular}

The volumes of the reduced list served the evaluation of the parameters of the GPD, the estimates of which are reported in the bottom part of Table 2 .

Figure 4 plots the volume-annual frequency of occurrence relationship given in Eq. (14). Even if the theory allows all the possible sizes bigger than $V_{\mathrm{t}}$ to be defined, an upper threshold value can be introduced by taking into account the geostructural survey of the rock slope, which can give evidence of the maximum block size.

\subsection{Becco dell'Aquila site}

Becco dell'Aquila site (UTM: $341345,5074157,32, T$ ) is located on the eastern side of Mont Chétif (2343 m a.s.l.) in the municipality of Courmayeur at an altitude ranging from $1230 \mathrm{~m}$ to $1800 \mathrm{~m}$ a.s.l. The study area is largely composed of Mont Chétif gneisses, which are fine- to medium-grained

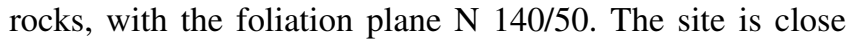
to a deposit of aggregates used for concrete production onto which a $20 \mathrm{~m}^{3}$ block fell on 5 May 2012. Despite a large rockfall event being recorded in 1903, systematic observations and monitoring activities on the site started in 1998.

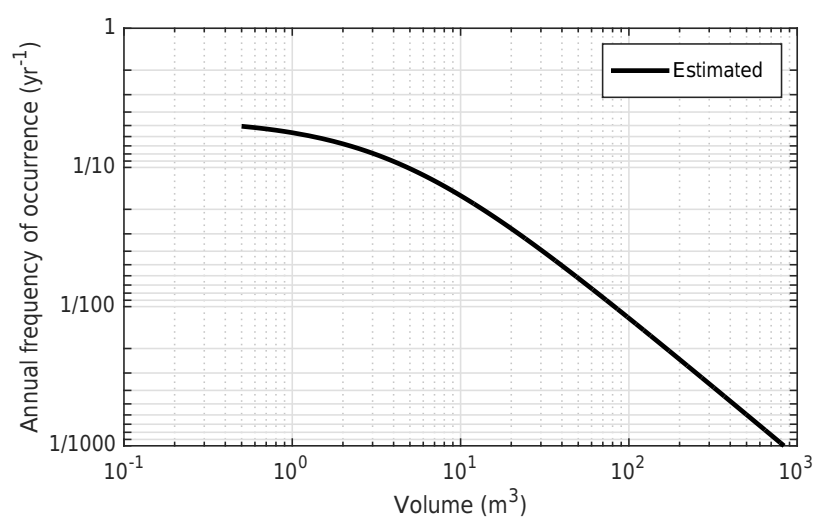

Figure 4. Volume-annual frequency of occurrence plot related to Buisson site.

An on-site survey was performed in the framework of a risk analysis for the activities at the foot of the slope. The block volumes were estimated by rough measurements and through the experience of a geologist. Blocks are grouped into size classes in a geometric progression following $2^{1 / 2}$ with volume, as reported in Table 3.

The historical catalogue of the Regional Geological Service of Aosta Valley reports three events in this site since 1998 (April 1998, April 2001, May 2012). The size of the fallen blocks is always larger than $5 \mathrm{~m}^{3}$. Considering that the slope is constantly monitored, it is evident that any event bigger than $5 \mathrm{~m}^{3}$ can be immediately observed and recorded. For this reason a threshold volume $V_{\mathrm{t}}=5 \mathrm{~m}^{3}$ was adopted. Catalogue $\mathcal{C}$ and the reduced catalogue $\mathcal{C}^{*}$ are coincident; see Table 4 for details.

The number of events considered in the analysis is equal to $n^{*}=n=3$. The corrected time $t^{*}$ is computed through Eq. (7) and is equal to 22.17 years. Eq. (15) gives $\lambda=0.1353$.

Referring to the distribution of the volumes, the reduced list, $\mathcal{F}^{*}$, was determined after the definition of the threshold volume (Table 3 ). The neglected data, i.e. belonging to volume classes smaller than $5 \mathrm{~m}^{3}$, are in italic in Table 3. The estimates of the GPD are reported in Table 4.

Based on the previously discussed data it was possible to obtain the volume-annual frequency of occurrence that is reported in Fig. 5 (grey line). A detailed survey of the potential instabilities in the source area showed that the maximum size of the detachable block is about $200 \mathrm{~m}^{3}$. Similarly, an additional truncated volume-annual frequency of occurrence relationship is plotted (dashed black line).

\section{Discussions and conclusions}

The definition of the relationship between the volumes that can stop on a slope and their return period is a parameter of paramount importance for a correct design procedure. The proposed methodology allows a volume-frequency law to be 
Table 3. List of the grouped volumes of the surveyed blocks on the slope of Becco dell'Aquila site. All the blocks belong to list $\mathcal{F}$; the blocks that are larger than $V_{\mathrm{t}}$, in normal font, belong to the reduced list $\mathcal{F}^{*}$. The blocks in italic are those that are not part of the reduced list $\mathcal{F}^{*}$.

\begin{tabular}{lrrc}
\hline $\begin{array}{l}\text { Volume } \\
\left(\mathrm{m}^{3}\right)\end{array}$ & $\begin{array}{r}\text { No. } \\
\text { records }\end{array}$ & $\begin{array}{r}\text { Volume } \\
\left(\mathrm{m}^{3}\right)\end{array}$ & $\begin{array}{c}\text { No. } \\
\text { records }\end{array}$ \\
\hline 1.000 & 10 & 16.000 & 6 \\
1.414 & 0 & 22.627 & 5 \\
2.000 & 8 & 32.000 & 2 \\
2.828 & 0 & 45.255 & 3 \\
4.000 & 3 & 64.000 & 0 \\
5.657 & 0 & 90.510 & 1 \\
8.000 & 26 & 128.000 & 1 \\
11.314 & 4 & 181.019 & 1 \\
\hline
\end{tabular}

Table 4. Input and results of the analyses performed on the Becco dell'Aquila site. The estimates of the parameters of the distribution are reported in the bottom rows (the standard deviations are detailed into brackets).

\begin{tabular}{ll}
\hline Obs. & $1998-2016$ \\
\hline$t$ & $19 \mathrm{yr}$ \\
$V_{\mathrm{t}}$ & $5 \mathrm{~m}^{3}$ \\
$n$ & 3 \\
$n^{*}$ & 3 \\
$t^{*}$ & $22.17 \mathrm{yr}$ \\
\hline$\lambda$ & 0.1353 \\
$\xi$ & 0.5509 \\
$\sigma$ & 7.7836 \\
$\mu$ & 5.0 \\
\hline
\end{tabular}

computed, which can be used in engineering calculations. Two different probabilistic models are considered: one for the Poisson's point process related to the occurrences of the events, the other for the fallen-block volume distributions (the GPD, which is independent of the year of rockfall occurrence). In order to make these considerations and use these probabilistic models, hypotheses are necessary.

The two probabilistic models are merged considering the hypothesis that the annual frequency of a rock block having a volume equal to the threshold volume is the parameter $\lambda$ of the Poisson distribution.

The events described by Poisson's probabilistic models need to be independent. In other words, no causality links have to subsist. Under this hypothesis, the process is random (Moller and Waagepetersen, 2003). In the framework of rockfalls, the validity of the hypothesis was discussed by McClung (1999), who stated that the interaction between a natural hazard and anthropic elements (e.g. vehicles, buildings) is a rare event that can be ascribed to a Poisson process.

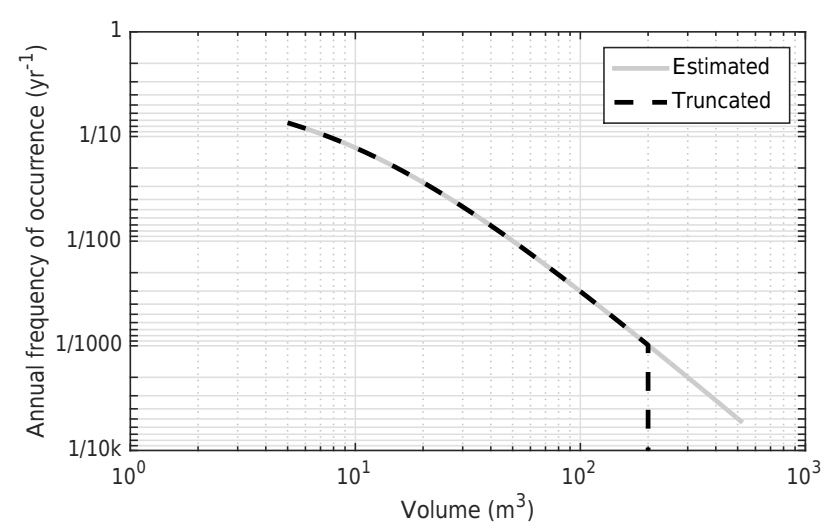

Figure 5. Volume-annual frequency of occurrence plot related to Becco dell' Aquila site.

Similarly, Lari et al. (2014) and Hantz and colleagues (Hantz et al., 2003; Hantz, 2011) invoke the same assumption.

The GPD has been chosen for fitting the values of list $\mathcal{F}$ for various reasons.

- Pareto family distributions are very similar to power law distributions except for the fact that the former are bounded distributions. The bound is represented by the location parameter $\mu$ in Eq. (9).

- GPD differs from the classical Pareto model for the introduction of a location parameter, which does not affect the slope of the right part of the plot, being governed by the exponent $-\xi^{-1}$.

- GPD is suitable for extreme value analysis. Pickands (1975) introduced it in the extreme value framework, as the distribution of a sample of exceedances above a certain high threshold.

In rockfall studies, the main distinction between GPD and power law can be observed when the value of the volume tends to zero. GPD is finite for $v \rightarrow 0$, while power law diverges to $\infty$, as required by scale invariance (Turcotte, 1997). That is, for the calculations proposed in the present paper, GPD and power law have the same right tail (linear in a log$\log$ plot), while for small volumes, the former is able to catch the fact that, although the volumes are close to the threshold value, $V_{\mathrm{t}}$, a finite number of blocks is counted in the representative area.

The degree of precision of the estimates of the parameters of a generalized Pareto distribution is determined through a bootstrap analysis (Efron and Tibshirani, 1994; BengoubouValerius and Gibert, 2013). This analysis allows us to determine the variance and the confidence bounds of the parameters of the GPD that fit each reduced list $\mathcal{F}^{*}$ of the previously considered rockfall sites. A 100000 bootstrap replications are made for each reduced list. For each replication, a bootstrap sample, i.e. a resampling of the reduced list, is gen- 
Table 5. Bootstrap statistical parameters of the estimates of the parameters of the generalized Pareto distribution related to the two example sites.

\begin{tabular}{lcc|cc}
\hline & \multicolumn{2}{c|}{ Buisson } & \multicolumn{2}{c}{ Becco dell'Aquila } \\
\cline { 2 - 5 } & $\xi$ & $\sigma$ & $\xi$ & $\sigma$ \\
\hline Mean & 0.937 & 4.919 & 0.511 & 8.104 \\
Variance & 0.166 & 4.511 & 0.032 & 2.226 \\
Median & 0.944 & 4.610 & 0.520 & 7.897 \\
$90 \%$ conf.b. & $(0.186,1.572)$ & $(2.247,8.481)$ & $(0.196,0.783)$ & $(6.088,10.871)$ \\
$95 \%$ conf.b. & $(0.093,1.705)$ & $(1.932,9.563)$ & $(0.103,0.831)$ & $(5.821,11.587)$ \\
\hline
\end{tabular}

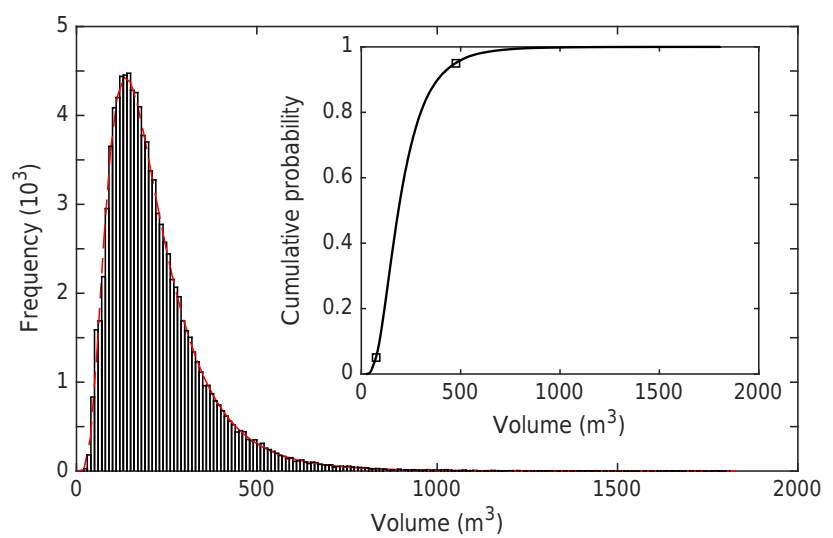

Figure 6. Histogram of the volumes having 1000 years return period fitted by a log-normal law (red dashed line). The empirical distribution function is plotted in the box: the squares bound the $90 \%$ confidence interval.

erated and an estimate of the parameters $\xi$ and $\sigma$ of the fitting generalized Pareto distribution is made.

From the set of the estimates of the parameters, the bootstrap mean, variance and median and the values of 90 and $95 \%$ confidence bounds are determined (Table 5). Note that the estimates of the parameters reported in Tables 2 and 4 are close to bootstrap medians.

In addition, for each bootstrap replication, once parameters $\xi$ and $\sigma$ are estimated, the volumes related to different ( 25 in total) return periods between 10 and 1000 years are computed through Eq. (12). As an example, the histogram of Fig. 6 shows the frequency of the 1000-year return period volumes obtained at Becco dell' Aquila: they are well fit by a log-normal law (red dashed line). The empirical distribution function is plotted in the box of Fig. 6. The values corresponding to cumulative probabilities of 0.05 and 0.95 are identified with squares. These corresponds to the bounds of the $90 \%$ confidence interval: in other words, this means that $90 \%$ of the volumes are larger than $73.8 \mathrm{~m}^{3}$ and smaller than $473.2 \mathrm{~m}^{3}$. Similarly, the bounds are determined on both sites for all the return periods considered in the range 10 1000 years. They are shown with dashes in Fig. 7.
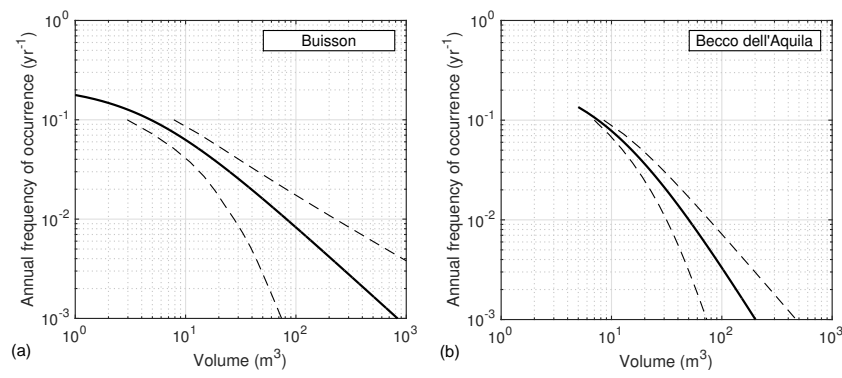

Figure 7. Results of the bootstrap analysis on the records on Buisson and Becco dell'Aquila sites. The continuous lines are plotted from Eq. (14) with the parameters reported in Tables 2 and 4. The dashed lines are the bounds of the $90 \%$ confidence intervals. In order to easily compare the two, the bounds of the axes are kept equal on the two plots.

It results that the width of the $90 \%$ confidence interval increases as much as the return period increases. This implies a spread of the value of the volumes of the blocks. Detailed and long records of the events as well as a proper survey of the volumes of the blocks would permit an increase in the quality of the volume-frequency law and, as a consequence, reduce the statistical errors in the procedure.

The proposed method allows the relationship between the return period and the volume of the blocks to be defined. This is a key aspect in land management and planning, design of protection devices (Peila et al., 1998, 2007; Keith Turner and Schuster, 2012; Mignelli et al., 2012, 2013; Dimasi et al., 2015) and for modern design approaches based on return periods of natural hazards (De Biagi et al., 2015, 2016a) and structural robustness (Cennamo et al., 2015; De Biagi and Chiaia, 2013; De Biagi, 2016). The bootstrap analysis has shown that the quality of the input data can affect the results particularly when long return periods are considered. Hence, in these cases, a critical analysis of the estimated volumes is required in the design process.

\section{Data availability}

The historical data can be accessed at http://catastodissesti. partout.it. 
Competing interests. The authors declare that they have no conflict of interest.

Acknowledgements. The authors acknowledge the two anonymous referees for their observations and comments of the manuscript. F. Laio is particularly acknowledged for having generously shared his experience and for his valuable comments. This research was supported by Regione Autonoma Valle d'Aosta under the framework of the project "Realizzazione di scenari di rischio per crolli di roccia".

Edited by: T. Glade

Reviewed by: two anonymous referees

\section{References}

Abbruzzese, J. M., Sauthier, C., and Labiouse, V.: Considerations on Swiss methodologies for rock fall hazard mapping based on trajectory modelling, Nat. Hazards Earth Syst. Sci., 9, 10951109, doi:10.5194/nhess-9-1095-2009, 2009.

Abellán, A., Calvet, J., Vilaplana, J., and Blanchard, J.: Detection and spatial prediction of rockfalls by means of terrestrial laser scanner monitoring, Geomorphology, 119, 162-171, 2010.

Abellán, A., Vilaplana, J. M., Calvet, J., García-Sellés, D., and Asensio, E.: Rockfall monitoring by Terrestrial Laser Scanning - case study of the basaltic rock face at Castellfollit de la Roca (Catalonia, Spain), Nat. Hazards Earth Syst. Sci., 11, 829-841, doi:10.5194/nhess-11-829-2011, 2011.

Bengoubou-Valerius, M. and Gibert, D.: Bootstrap determination of the reliability of $b$-values: an assessment of statistical estimators with synthetic magnitude series, Nat. Hazards, 65, 443-459, 2013.

Brunetti, M. T., Guzzetti, F., and Rossi, M.: Probability distributions of landslide volumes, Nonlin. Processes Geophys., 16, 179-188, doi:10.5194/npg-16-179-2009, 2009.

Burnham, K. P. and Anderson, D. R.: Model selection and multimodel inference: a practical information-theoretic approach, Springer Science \& Business Media, 2003.

Cennamo, C., Chiaia, B., De Biagi, V., and Placidi, L.: Monitoring and compartmentalized structures, ZAMM-Z. Angew. Math. Me., 95, 638-648, 2015.

Claps, P. and Laio, F.: Can continuous streamflow data support flood frequency analysis? An alternative to the partial duration series approach, Water Resour. Res., 39, 1216, doi:10.1029/2002WR001868, 2003.

Corominas, J., Copons, R., Moya, J., Vilaplana, J., Altimir, J., and Amigó, J.: Quantitative assessment of the residual risk in a rockfall protected area, Landslides, 2, 343-357, 2005.

Corominas, J., Mavrouli, O., Santana, D., and Moya, J.: Simplified approach for obtaining the block volume distribution of fragmental rockfalls, Landslides and engineered slopes, Taylor and Francis, 2, 1159-1164, 2012.

Corominas, J., Van Westen, C., Frattini, P., Cascini, L., Malet, J.-P., Fotopoulou, S., Catani, F., Van Den Eeckhaut, M., Mavrouli, O., Agliardi, F., Pitilakis, K., Winter, M. G., Pastor, M., Ferlisi, S., Tofani, V., Hervás, J., and Smith, J. T.: Recommendations for the quantitative analysis of landslide risk, B. Eng. Geol. Environ., 73, 209-263, 2014.

Crosta, G., Frattini, P., and Fusi, N.: Fragmentation in the Val Pola rock avalanche, Italian Alps, J. Geophys. Res.-Earth, 112, F01006, doi:10.1029/2005JF000455, 2007.

Dai, F. and Lee, C.: Frequency-volume relation and prediction of rainfall-induced landslides, Eng. Geol., 59, 253-266, 2001.

De Biagi, V.: Structural behavior of a metallic truss under progressive damage, Int. J. Solids Struct., 82, 56-64, 2016.

De Biagi, V. and Chiaia, B.: Complexity and robustness of frame structures, Int. J. Solids and Struct., 50, 3723-3741, 2013.

De Biagi, V., Chiaia, B., and Frigo, B.: Fractal grain distribution in snow avalanche deposits, J. Glaciol., 58, 340-346, 2012.

De Biagi, V., Chiaia, B., and Frigo, B.: Impact of snow avalanche on buildings: Forces estimation from structural back-analyses, Eng. Struct., 92, 15-28, 2015.

De Biagi, V., Barbero, M., and Borri-Brunetto, M.: A reliabilitybased method for taking into account snowfall return period in the design of buildings in avalanche-prone areas, Nat. Hazards, 81, 1901-1912, 2016a.

De Biagi, V., Botto, A., Napoli, M., Dimasi, C., Laio, F., Peila, D., and Barbero, M.: Calcolo del tempo di ritorno dei crolli in roccia in funzione della volumetria, GEAM Geoingegneria Ambientale e Mineraria, LIII, 39-48, 2016b.

Dewez, T., Rohmer, J., Regard, V., and Cnudde, C.: Probabilistic coastal cliff collapse hazard from repeated terrestrial laser surveys: case study from Mesnil Val (Normandy, northern France), J. Coastal Res., 65, 702-707, 2013.

Dimasi, C., Luciani, A., Martinelli, D., Paganone, M., and Peila, D.: Controllo delle barriere paramassi a rete per la loro gestione e manutenzione, GEAM. GEOINGEGNERIA AMBIENTALE E MINERARIA, 146, 65-73, 2015.

Dorren, L., Berger, F., Jonsson, M., Krautblatter, M., Mölk, M., Stoffel, M., and Wehrli, A.: State of the art in rockfall-forest interactions, Schweizerische Zeitschrift fur Forstwesen, 158, 128141, 2007.

Dussauge, C., Grasso, J.-R., and Helmstetter, A.: Statistical analysis of rockfall volume distributions: Implications for rockfall dynamics, J. Geophys. Res.-Sol. Ea., 108, 2286, doi:10.1029/2001JB000650, 2003.

Dussauge-Peisser, C., Helmstetter, A., Grasso, J.-R., Hantz, D., Desvarreux, P., Jeannin, M., and Giraud, A.: Probabilistic approach to rock fall hazard assessment: potential of historical data analysis, Nat. Hazards Earth Syst. Sci., 2, 15-26, doi:10.5194/nhess-2-15-2002, 2002.

Efron, B. and Tibshirani, R.: An introduction to the bootstrap, CRC press, 1994.

Elishakoff, I.: Probabilistic Theory of Structures, Courier Dover Publications, 1999.

Gardner, J.: Rockfall: a geomorphic process in high mountain terrain, Albertan Geographer, 6, 15-20, 1970.

Gutenberg, B. and Richter, C. F.: Earthquake magnitude, intensity, energy, and acceleration (second paper), B. Seismol. Soc. Am., 46, 105-145, 1956.

Guzzetti, F., Cardinali, M., and Reichenbach, P.: The AVI Project: A bibliographical and archive inventory of landslides and floods in Italy, Environ. Manage., 18, 623-633, 1994.

Guzzetti, F., Reichenbach, P., and Wieczorek, G. F.: Rockfall hazard and risk assessment in the Yosemite Valley, California, USA, 
Nat. Hazards Earth Syst. Sci., 3, 491-503, doi:10.5194/nhess-3491-2003, 2003.

Hantz, D.: Quantitative assessment of diffuse rock fall hazard along a cliff foot, Nat. Hazards Earth Syst. Sci., 11, 1303-1309, doi:10.5194/nhess-11-1303-2011, 2011.

Hantz, D., Vengeon, J. M., and Dussauge-Peisser, C.: An historical, geomechanical and probabilistic approach to rock-fall hazard assessment, Nat. Hazards Earth Syst. Sci., 3, 693-701, doi:10.5194/nhess-3-693-2003, 2003.

Hantz, D., Ventroux, Q., Rossetti, J., and Berger, F.: A new approach of diffuse rockfall hazard, in: Landslides and Engineered Slopes. Experience, Theory and Practice: Proceedings of the 12th International Symposium on Landslides, edited by: Aversa, S., Cascini, L., Picarelli, L., and Scavia, C., vol. 2, 1063-1068, 2016.

Hungr, O., Evans, S., and Hazzard, J.: Magnitude and frequency of rock falls and rock slides along the main transportation corridors of southwestern British Columbia, Can. Geotech. J., 36, 224238, 1999.

ISO: General Principles on reliability for structures ISO 2394:1998, International Organization for Standardization, 1998.

Jaboyedoff, M., Couture, R., and Locat, P.: Structural analysis of Turtle Mountain (Alberta) using digital elevation model: toward a progressive failure, Geomorphology, 103, 5-16, 2009.

Keith Turner, A. and Schuster, R. L.: Rockfall: characterization and control, Transport Research Board of the National academies, 2012.

Lari, S., Frattini, P., and Crosta, G.: A probabilistic approach for landslide hazard analysis, Eng. Geol., 182, 3-14, 2014.

Leporati, E.: The Assessment of Structural Safety, Research Studies, USA, 1979

Madsen, H., Krenk, S., and Lind, N.: Methods of structural safety, Courier Dover Publications, 2006.

Mavrouli, O., Corominas, J., and Jaboyedoff, M.: Size Distribution for Potentially Unstable Rock Masses and In Situ Rock Blocks Using LIDAR-Generated Digital Elevation Models, Rock Mechanics and Rock Engineering, 48, 1589-1604, 2015.

McClung, D.: The encounter probability for mountain slope hazards, Can. Geotech. J., 36, 1195-1196, 1999.

Melchers, R.: Structural Reliability Analysis and Prediction, Wiley, 1999.

Mignelli, C., Lo Russo, S., and Peila, D.: ROckfall risk MAnagement assessment: the RO. MA. approach, Nat. Hazards, 62, 1109-1123, 2012.

Mignelli, C., Pomarico, S., and Peila, D.: Use of Multi-Criteria Model to Compare Devices for the Protection of Roads against Rockfall, Environ. Eng. Geosci., 19, 289-302, 2013.
Moller, J. and Waagepetersen, R.: Statistical inference and simulation for spatial point processes, CRC Press, 2003.

Moya, J., Corominas, J., and Arcas, J.: Assessment of the rockfall frequency for hazard analysis at Solà d'Andorra (Eastern Pyrenees), in: Tree Rings and Natural Hazards, Springer, 161-175, 2010.

Peila, D. and Ronco, C.: Technical Note: Design of rockfall net fences and the new ETAG 027 European guideline, Nat. Hazards Earth Syst. Sci., 9, 1291-1298, doi:10.5194/nhess-9-1291-2009, 2009.

Peila, D., Pelizza, S., and Sassudelli, F.: Evaluation of behaviour of rockfall restraining nets by full scale tests, Rock Mech. Rock Eng., 31, 1-24, 1998.

Peila, D., Oggeri, C., and Baratono, P.: Barriere paramassi a rete, Interventi e dimensionamento, Quaderni, GEAM, 2006.

Peila, D., Oggeri, C., and Castiglia, C.: Ground reinforced embankments for rockfall protection: design and evaluation of full scale tests, Landslides, 4, 255-265, 2007.

Pickands, J.: Statistical inference using extreme order statistics, the Annals of Statistics, 119-131, 1975.

Rosser, N., Petley, D., Lim, M., Dunning, S., and Allison, R.: Terrestrial laser scanning for monitoring the process of hard rock coastal cliff erosion, Q. J. Eng. Geol. Hydroge., 38, 363-375, 2005.

Rousseau, N.: Study of seismic signals associated with rockfalls at 2 sites on the Reunion island (Mahavel Cascade and Souffriere cavity), PhD thesis, IPG, Paris, 1999.

Ruiz-Carulla, R., Corominas, J., and Mavrouli, O.: A methodology to obtain the block size distribution of fragmental rockfall deposits, Landslides, 12, 815-825, 2015.

Ruiz-Carulla, R., Corominas, J., and Mavrouli, O.: Comparison of block size distributions in rockfall, in: Landslides and Engineered Slopes, Experience, Theory and Practice: Proceedings of the 12th International Symposium on Landslides, edited by: Aversa, S., Cascini, L., Picarelli, L., and Scavia, C., vol. 3, $1767-$ 1774, 2016.

Stark, C. and Hovius, N.: The characterization of landslide size distributions, Geophys. Res. Lett., 28, 1091-1094, 2001.

Straub, D. and Schubert, M.: Modeling and managing uncertainties in rock-fall hazards, Georisk, 2, 1-15, 2008.

Turcotte, D.: Fractals and chaos in geology and geophysics, Cambridge University Press, 1997.

Wieczorek, G. and Snyder, J.: Historical rock falls in Yosemite National Park, California, US Geological Survey, 2004. 